\title{
The effects of chlorpromazine upon fear-motivated behavior in the squirrel monkey
}

\author{
VINCENT P. HOUSER \\ Psychotropic Drug Laboratory, Veterans Administration Hospital, Perry Point, Maryland 21902
}

\begin{abstract}
Four male squirrel monkeys were subjected to a Sidman nondiscriminated avoidance schedule (R-S, $\mathrm{S}-\mathrm{S}-20 \mathrm{sec}$ ) that superimposed 3 -min conditioned stimuli (CS)/unavoidable shock pairings upon ongoing avoidance behavior. Three of the four animals demonstrated facilitated avoidance and activity rates during the CS, while one animal demonstrated suppressed avoidance and activity trates during the CS. Chlorpromazine $(.05, .10, .20 \mathrm{mg} / \mathrm{kg})$ reduced overall response rates and augmented shock rates significantly in a dose-related manner. The facilitation ratios computed to reflect the degree of response facilitation for three of the animals during the aversive CS were not significantly altered by drug administration. The one animal which normally suppressed its rate during the CS, however, demonstrated an attenuation of this suppression under all doses of the drug. These results were interpreted to suggest that the degree of behavioral facilitation noted during an aversive CS cannot be used as a sensitive index of the anxiolytic properties of drugs.
\end{abstract}

This laboratory has been interested in developing a behavioral schedule that is sensitive to the anxiolytic properties of drugs. To this end, we have evaluated the effects of various compounds upon the traditional conditioned emotional response (CER) paradigm which superimposes conditioned stimuli (CS) shock presentations upon ongoing behavior maintained by an appetitive schedule of reinforcement (Houser, Note 1). Although some investigators have used this procedure to assess the fear-reducing properties of drugs (Brady, 1956, 1967; Vogel, Hughes, \& Carlton, 1967), this schedule does have the disadvantage of being affected by drug-induced anorexia. Thus, agents that produce anorexia can reduce baseline response rates to such low levels that reliable changes in rate during the $\mathrm{CS}$ are impossible to measure (Houser, Note 1). In order to circumvent this difficulty, our laboratory has utilized a modified CER paradigm which employs a nondiscriminated Sidman avoidance rather than an appetitive schedule to maintain the ongoing behavior. Thus, under this modified procedure, CS-shock presentations are delivered while animals are performing an operant avoidance response. Many investigators (Herrnstein \& Conrad, 1957; Herrnstein \& Sidman, 1958; Rescorla, 1967; Sidman, 1958) have reported that under this combination schedule avoidance rates are augmented in the presence of the CS. This facilitation of rate during the $\mathrm{CS}$ is maintained even when the avoidance response has been extinguished (Kelleher,

The author would like to express his appreciation to Mr. Luther R. Gilliam, Chief of the Medical Illustration Service, VA Hospital, Perry Point, Maryland, for his assistance in preparing the figures that appear in this paper. Thanks are also due Mr. Randall J. Cash for his technical assistance and to Mrs. Dale A. Van Hart for her help in preparing the manuscript. Present address of Vincent P. Houser is RD No. 1, Box B95, Route 94, Chester, New York 10918.
Riddle, \& Cook, 1963; Waller \& Waller, 1963) or when baseline avoidable shocks are omited during the CS (Houser, 1972, 1973). This evidence has been interpreted as support for the two-process learning theories, which postulate that Pavlovian CRs motivate instrumental responses (Maier, Seligman, \& Solomon, 1969). Thus, since both this instrumental avoidance response and the Pavlovian conditioned response are motivated by fear, combining the two responses in one behavioral schedule increases the level of fear during the Pavlovian CS, as indicated by the increased instrumental response rates.

The assumption that enhanced levels of fear during the aversive CS produce facilitation of avoidance behavior is appealing since this behavioral response could provide a useful index of the anxiolytic properties of various drugs. During training trials, we have noticed that animals (i.e., monkeys and dogs) demonstrate facilitated avoidance response rates during the aversive CS that are directly related to the intensity of shock that is utilized in this schedule. Thus, the degree of facilitation noted during the CS appears to be a function of the amount of fear associated with the aversive stimulus. Furthermore, the avoidance behavior exhibited during the CS appears to be more sensitive to drug effects than behavior noted during non-CS segments of the schedule. Previous reports (Houser \& Cash, 1975) have indicated that morphine sulfate, a potent analgesic agent, was able to selectively lower response rates during the aversive CS in doses that did not significantly alter baseline avoidance behavior. These data thus suggest that a drug which reduces the aversive or fear-producing qualities of shock selectively affects behavior during the CS to a greater degree than behavior generated during non-CS segments of the schedule. This may be the case since the fear produced by the aversive CS has been 
associated with a low shock density (i.e., one shock/ 3-min CS), while the fear underlying baseline performance has been associated with a high-shock density (i.e., one potential shock $/ 20 \mathrm{sec}$ ). A drug which reduces fear motivation to any appreciable degree would thus be expected to produce decrements in behavior associated with a low shock density before it affected response rates associated with a high shock density. If this analysis is correct, the above schedule might be useful in assaying the anxiolytic properties of a variety of pharmaceutical agents.

Unfortunately, other evidence does not support the above assumption that enhanced levels of fear during the CS produce facilitation of the avoidance response or that behavior during the CS is more sensitive to drug effects than baseline avoidance response rates. Many investigators (Houser, 1973; Houser \& Cash, 1975; Houser \& Houser, 1973; Pomerleau, 1970; Scobie, 1972) have noted that under certain conditions rats and monkeys will demonstrate suppressed Sidman avoidance rates in the presence of an aversive CS. Furthermore, recent evidence from this laboratory (Houser, Rothfeld, \& Varady, 1975) has indicated that the minor tranquilizer, chlordiazepoxide, did not selectively affect the facilitation of heart, avoidance response, and activity rates normally noted during the aversive CS in dogs. In order to obtain more evidence upon whether this particular schedule can, in fact, detect the anxiolytic properties of drugs, the present paper explored the effects of a major tranquilizing agent, chlorpromazine, upon behavior noted during an aversive $\mathrm{CS}$ in squirrel monkeys.

\section{METHOD}

\section{Subjects}

The subjects in this experiment consisted of four male squirrel monkeys (Saimiri sciureus), ranging in weight from 454 to $794 \mathrm{~g}$. All animals were kept on ad-lib food (Purina Monkey Chow) and water diets throughout the experimental period. All animals had extensive experience with the avoidance schedules outlined below and had been administered various drugs prior to their use in the present experiment.

\section{Apparatus}

All animals were tested in one of two Plexiglas restraint chairs (Lehigh Valley Electronics, Model 142-10). Shock was applied to a shaved portion of the animal's tail via two brass electrodes that were placed on the skin surface. A plastic lock around the base of the tail and rubber band around the two electrodes insured that the animal could not move the position of the electrodes during the session. The shock stimulus was provided by a high-voltage $(2,780 \mathrm{~V})$ ac source which placed a large resistance $(540 \mathrm{~K})$ in series with the animal's tail. Thus, minor fiuctuations in tissue impedance would not affect current intensity to any appreciable degree. To further insure that the shock stimulus was constant between experimental sessions, impedance was monitored across the animal's tail by a Triplett (Model 630-A) multimeter before each session to insure that it remained at 3,200 ohms $( \pm 100 \mathrm{ohms})$. This relatively constant impedance between sessions was made possible by applying small amounts of Redux electrode paste between each electrode and the animal's skin. A response lever (Lehigh Valley Electronics, Model 121-05) was located directly in front of the animal and required a downward pressure of $10 \mathrm{~g}$ to activate the microswitch. The houselight (TS-304-28 VDC) located directly above the animal's head served as the only light in the experimental chamber. In order to obtain a measure of general motor activity, each restraint chair was suspended from a wooden enclosure in a way that allowed the chair to swing in any lateral direction when the animal moved. This movement was recorded by two concentric brass rings which were connected to the chair and the fixed wooden enclosure, respectively. These brass rings acted as electrical contacts which served to trigger an electronic counting device whenever animal movements caused the two brass rings to come into contact. A more detailed description of this measure has been presented previously (Love \& Houser, 1973). To diminish the possibility that extraneous sounds would disrupt the animal's performance, white noise $(90 \mathrm{~dB})$ was presented via a speaker mounted inside the enclosure. Standard scheduling and recording equipment were located in an adjacent room.

\section{Procedure}

Initial training. All four animals were initially trained to press the response lever to escape shock by a method of autoshaping. Animals were placed in the restraining chair, and electrodes were fastened to the tail. The behavioral schedule commenced upon closure of the environmental chamber door and onset of the houselight. The schedule consisted of a Sidman nondiscriminated avoidance procedure with a response-shock (R-S) and a shock-shock (S-S) interval of $20 \mathrm{sec}$. The shock intensity was placed at $3 \mathrm{~mA}$ for a maximum duration of $5.0 \mathrm{sec}$. Animals could escape the shock by simply depressing the lever located in the restraint chair, thus terminating the shock and postponing onset of the next shock for $20 \mathrm{sec}$. Every leverpress response made during the R-S interval postponed shock for another $20 \mathrm{sec}$. All animals quickly learned to escape and then avoid these shocks by making the appropriate leverpress response within the first few sessions. After 10 2-h sessions (i.e., $20 \mathrm{~h}$ ), the shock duration was decreased to a maximum of $.8 \mathrm{sec}$, while the intensity was increased to $5 \mathrm{~mA}$ for the remainder of the experimental period.

Animals were then subjected to 302 -h daily sessions (i.e. $60 \mathrm{~h}) 5$ days/week, to establish stable avoidance baselines. After this training, CS habituation trials were given during five consecutive 2-h daily sessions. Under these conditions, 3-min CSs were presented at 18-min intervals throughout the session. The CS consisted of dimming the houselight by connecting a 100-ohm resistor in series with the $28-\mathrm{V}$ houselight. After five sessions, no change in response rate was noted during the CS for any of the animals. At this point, unavoidable shocks were programmed to occur simultaneously with offset of each of the five CSs presented during each daily session. These unavoidable shocks were of the same intensity and duration as the avoidable shocks (i.e., $5 \mathrm{~mA}-.8 \mathrm{sec}$ ). Animals were then subjected to lengthy testing sessions (i.e., several thousand hours) in which various drugs were administered. Fifty experimental sessions (i.e., $100 \mathrm{~h}$ ) in which no drugs were administered immediately preceded the chlorpromazine drug trials.

Drug trials. Chlorpromazine was administered intramuscularly (IM) in saline at a volume of $.5 \mathrm{ml} / \mathrm{kg}$ of body weight. Each dose of the drug was administered in three consecutive daily sessions, preceded by three consecutive saline sessions. All drug or saline injections were given immediately before the animals were placed in the restraint chair for the daily 2-h experimental sessions. The drug dosages were given in the following order to each of the four subjects: $.05, .10, .20 \mathrm{mg} / \mathrm{kg}$. The entire drug portion of the study extended for 18 days. 


\section{RESULTS}

The behavioral measures taken during this experiment consisted of the total number of leverpressing responses made during the 2 -h daily sessions, as well as the total number of shocks received. In addition, the cumulative number of responses made during the $3 \mathrm{~min}$ preceding onset of each CS were recorded, along with the cumulative number of responses emitted during the five daily CS presentations, on two separate electronic counters. These two measures made it possible to determine if the CS affected response rate by simply comparing the rates emitted immediately before $\mathrm{CS}$ onset with rates during the CS. These comparisons were made by computing a ratio first described by Annau and Kamin (1961). The ratio is B/(A + B), where $B$ represents the number of avoidance responses emitted during the CS, and $A$ the number of avoidance responses during the $3 \mathrm{~min}$ before CS onset. This ratio has limits of 0.00 (representing total suppression during the CS) and 1.00 (representing no responses before the CS with some occurring during the CS). A ratio of .50 would indicate no change in rate during the CS; ratios below this represent suppression, and ratios above .50 represent facilitation.

Finally, a measure of general motor activity was obtained for each animal during every drug and saline session which consisted of the total number of counts recorded from the activity apparatus described above. In addition, a facilitation or suppression ratio for activity was computed from two separate counters which recorded the amount of activity emitted $3 \mathrm{~min}$ before and during each aversive $\mathrm{CS}$. These ratios were computed in the same manner as the response ratios described above.

Figure 1 presents the mean number of responses, shocks, and activity counts with corresponding standard error of the means for all four monkeys during the entire experimental period. Probability levels are given for statistical comparisons (i.e., $t$ tests for related samples, two-tailed) made between consecutive saline and drug dosage series. As the data in Figure 1 indicate, chlorpromazine produced doserelated decrements in the number of avoidance responses emitted. In addition, the drug produced concomitant increases in the mean number of shocks that were highly significant. Under the highest dose (i.e., $.20 \mathrm{mg} / \mathrm{kg}$ ), several animals demonstrated a complete loss of the avoidance response, and thus received a shock every $20 \mathrm{sec}$. This effect appeared more pronounced during the 2 nd and 3rd days this dose was administered. Finally, mean activity was reliably reduced only under the lowest dose (i.e., $.05 \mathrm{mg} / \mathrm{kg}$ ) of the drug.

Table 1 presents the mean response and activity ratios for all four monkeys during the various saline

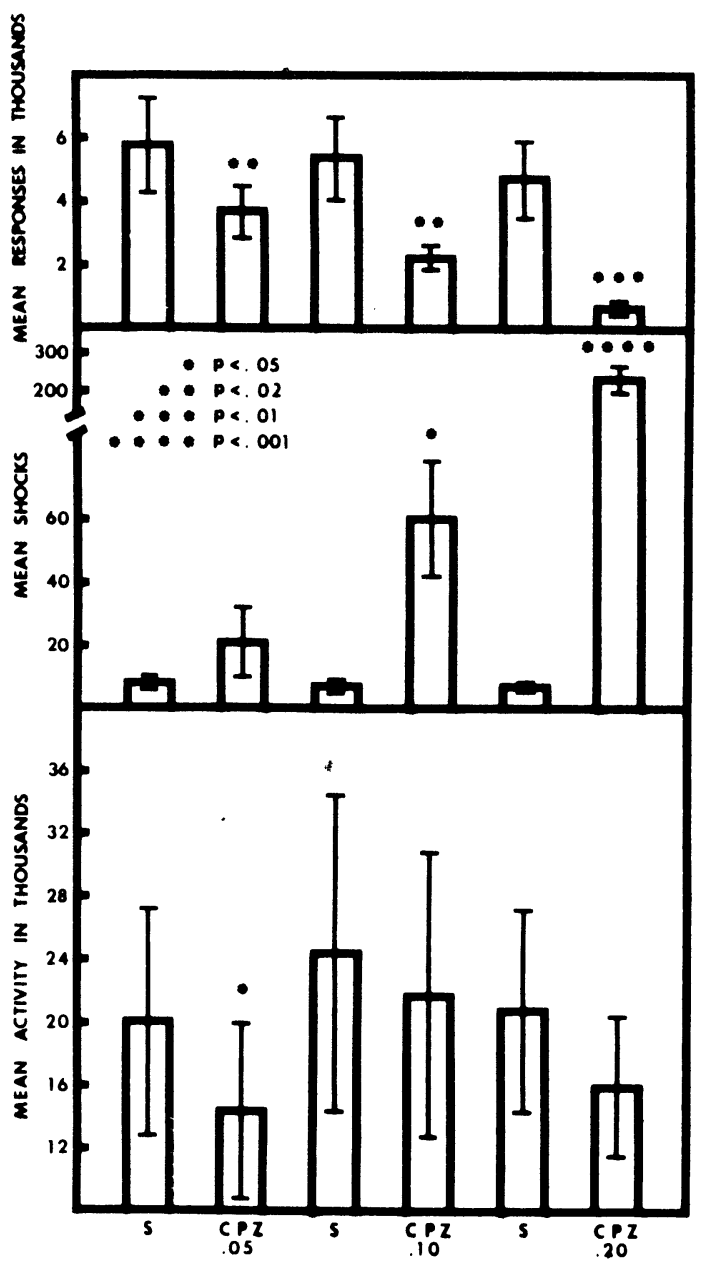

Figure 1. Mean number of responses, shocks, and activity counts with corresponding standard error of the means for the four squirrel monkeys during the saline (S) and various drug dosage sessions. Each bar represents the mean of three consecutive drug or saline sessions. All drug dosages are given in milligrams/kilogram.

and drug sessions. These data indicate that the one animal that normally suppressed its response rates during the aversive CS showed increased suppression ratios under the two lower doses, and demonstrated facilitated response rates during the $\mathrm{CS}$ under the highest (i.e., $.20 \mathrm{mg} / \mathrm{kg}$ ) dosage of chlorpromazine. Thus, in this one animal, the response suppression ratios showed dose-related increments after the administration of chlorpromazine. No consistent drug effects were noted, however, with regard to the activity ratios for this animal.

The three animals that normally demonstrated facilitated rates during the aversive CS (i.e., had control response ratios above .50) demonstrated slight mean increases in these ratios at all three doses tested, but none of these changes were statistically significant. Likewise, the activity ratios showed little change under the two lower doses of this drug. However, the highest 
Table 1

Mean Response and Activity Ratios for All Four Monkeys During Saline and Drug Sessions

\begin{tabular}{clcccccc}
\hline & & CPZ & & CPZ & CPZ \\
& & Saline & $.05^{*}$ & Saline & .10 & Saline \\
\hline Suppressor & Response Ratio & .41 & .44 & .43 & .49 & .39 & .60 \\
$\mathrm{~N}=1$ & Activity Ratio & .45 & .46 & .47 & .47 & .40 & .48 \\
Facilitators & Response Ratio & .69 & .71 & .65 & .67 & .64 & .85 \\
$\mathrm{~N}=3$ & Activity Ratio & .89 & .88 & .87 & .89 & $.57 *$ \\
\hline & \multirow{2}{*}{ All drug dosages given in milligroms per kilogram. } & & $* *^{*} p<.05$.
\end{tabular}

dose $(.20 \mathrm{mg} / \mathrm{kg})$ produced a statistically significant (i.e., as computed using $\mathrm{t}$ tests for related samples) reduction in the mean activity ratio. To summarize, the data in Table 1 indicate that chlorpromazine did not consistently alter the response or activity ratios generated by the majority of animals tested. Thus, the decrements in response rate noted after drug administration were distributed equally across the CS and non-CS segments of the schedule for the three animals who demonstrated facilitation of avoidance rates during the aversive $\mathrm{CS}$.

Figure 2 presents selected cumulative records of two representative animals under saline or chlorpromazine $(.10 \mathrm{mg} / \mathrm{kg})$. The left-hand portion of this figure indicates that one animal, ABBY, normally suppressed its avoidance rate in the presence of the 3-min CS, as indicated by the reduced slope of the response line during this period. After offset of the CS and the concurrent unavoidable shock, this animal resumed its normal or accelerated response rate. Under the influence of $.10 \mathrm{mg} / \mathrm{kg}$ of chlorpromazine, the response rate of this animal was reduced, leading to more baseline shocks. Furthermore, as was noted in Table 1, the response suppression normally noted during the CS was abolished, and in some cases (i.e., second CS presentation in Figure 2), response facilitation was recorded under drug conditions.

The right-hand portion of Figure 2 presents the performance of another animal, JERRY, which normally demonstrated facilitated avoidance response rates during the aversive CS, as noted by the increased slope of the response line in the saline record. Under $.10 \mathrm{mg} / \mathrm{kg}$ of chlorpromazine, the baseline response rate was reduced considerably, producing an increase in the number of shocks received. The relative facilitation of response rate normally noted during the CS was unaffected, however, during drug administration.

\section{DISCUSSION}

The present data indicate that chlorpromazine was

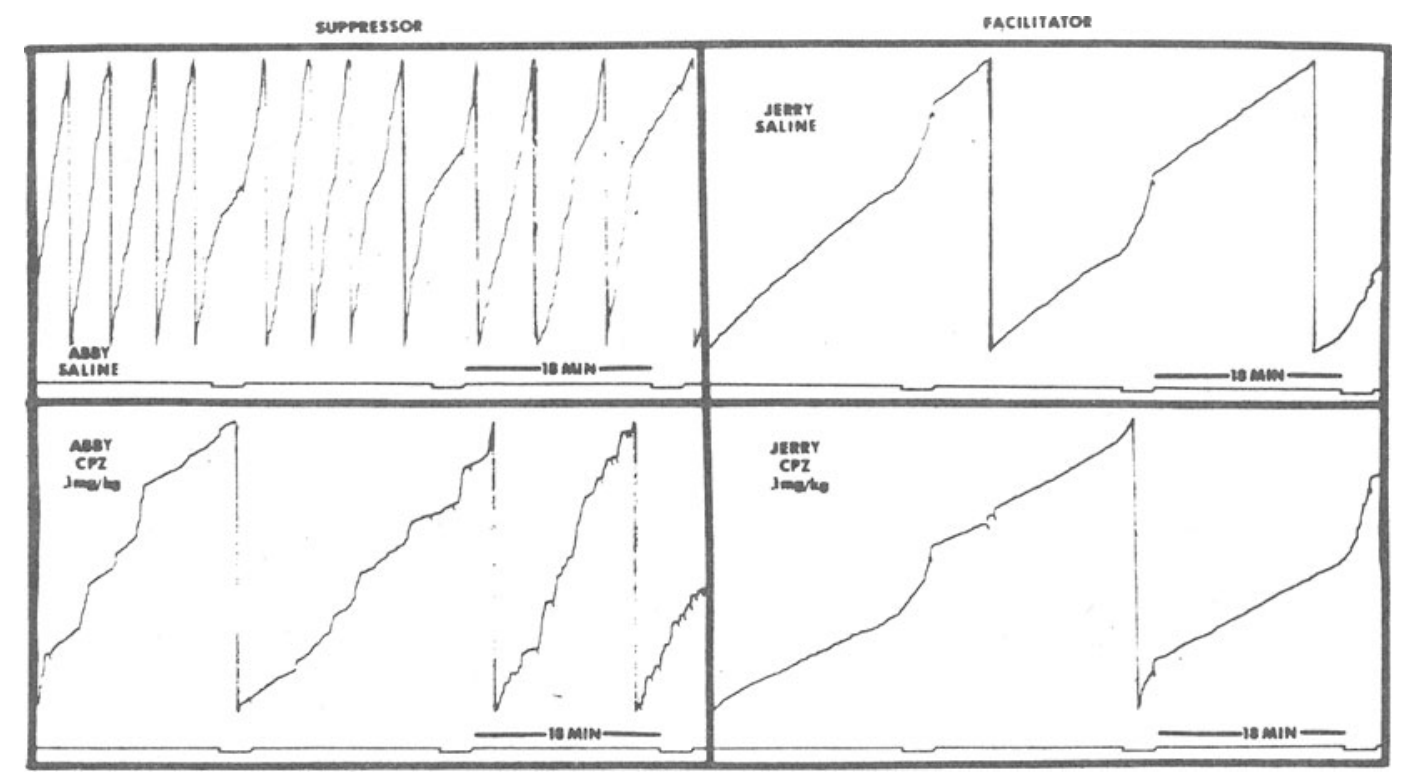

Figure 2. Selected cumulative records of two representative animals under saline or chlorpromazine $(.10 \mathrm{mg} / \mathrm{kg}) \mathrm{conditions}$. The bottom line in each record represents the time base. Deflections in the bottom line represent the 3-min CS. The top line represents the response rate. Deflections in the top line represent shocks received. Response rate is indicated by the slope of the response line: the greater the slope, the greater the response rate. A complete excursion across the record by the response pen represents approximately 500 leverpress responses. All records represent performance during Minute 1 through 63 of the 120-min (2-h) session. 
able to reliably reduce baseline avoidance response rate, thus producing elevated shock rates in a dose-related manner. Activity rates were reduced only under the lowest dosage. This may have been the case since $.05 \mathrm{mg} / \mathrm{kg}$ was the only dosage that did not elevate the shock rate significantly. Animals usually move violently in the chair whenever they receive a shock. Under the two highest doses, animals received considerably more shocks, which may have elevated general activity to the point where the sedative effects of the drug were obliterated. Finally, the relative activity and response rates during the aversive CS were unaffected under drug conditions in animals which demonstrated facilitation. The one animal which normally suppressed its response rates during the CS, however, did demonstrate less response suppression under drug conditions.

The present results support previous reports that have indicated that chlorpromazine can produce decrements in Sidman avoidance behavior in monkeys (Cook \& Kelleher, 1962, 1963). As in the present data, sufficiently high dosages (i.e., $2.0 \mathrm{mg} / \mathrm{kg} P O$ ) were reported to block all responding under a nondiscriminated avoidance schedule (Cook \& Kelleher, 1962). In addition, our negative data with regard to relative rates during the aversive CS corroborate earlier work that reported results using the traditional CER paradigm which makes use of an appetitive schedule of reinforcement. Both Lauener (1963) and Ray (1964) have noted that chlorpromazine did not affect the suppression of an appetitive response during an aversive CS in rats. It would thus appear that changes in relative response rates during an aversive CS cannot be used as a sensitive index of the anxiolytic properties of the major tranquilizer, chlorpromazine. This fact, coupled with the knowledge that the minor tranquilizer, chlordiazepoxide, is inactive in the dog under the same schedule (i.e., CER paradigm using an avoidance baseline; Houser, Rothfeld, \& Varady, 1975), leads one to conclude that behavioral tests that utilize an aversive CS may not be useful in assaying the anxiolytic properties of drugs. The fact that one animal in the present study which normally suppressed its rates during the CS did react to all doses of chlorpromazine suggests that those monkeys which do suppress may be more likely to respond to the anxiolytic properties of drugs. Although this may be the case, several factors make the use of behavioral suppression impractical as an index of drug activity. Experience in our laboratory has indicated that suppression of the avoidance response appears in only a minority of monkeys tested and, furthermore, that suppression tends to be a less stable response than facilitation. Thus, it appears that changes in relative rate during an aversive CS cannot be used as a reliable index of the anxiolytic properties of drugs.

\section{REFERENCE NOTES}

1. Houser, V. P. Adrenergic drugs and conditioned fear. Edgewood Arsenal Technical Report, 1972, 4668, 1-21.

2. Houser, V. P. The effects of drugs upon a modified Sidman avoidance schedule that employs response independent shock. A preliminary report on cholinergic agents. Edgewood Arsenal Technical Report, 1972, 4663, 1-25.

\section{REFERENCES}

Annau, Z., \& Kamin, L. J. The conditioned emotional response as a function of intensity of the US. Journal of Comparative and Physiological Psychology, 1961, 54, 428-432.

BRADY, J. V. Assessment of drug effects on emotional behavior. Science, 1956, 123, 1033-1034.

BraDY, J. V. Emotion and the sensitivity of psychoendocrine systems. In D. C. Glass (Ed.), Neurophysiology and emotion. New York: The Rockefeller University Press, 1967. Pp. 70-95.

Cook, L., \& Kelleher, R. T. Drug effects on the behavior of animals. Annals of the New York Academy of Science, 1962, 96, 315-335.

Cook, L., \& Kelleher, R. T. Effects of drugs on behavior. Annual Review of Pharmacology, 1963, 3, 205-222.

Herronstein, R. J., \& Sidman, M. Avoidance conditioning as a factor in the effects of unavoidable shocks on foodreinforced behavior. Journal of Comparative and Physiological Psychology, 1958, 51, 380-385.

Houser, V. P. Modulation of avoidance behavior in squirrel monkeys after chronic administration and withdrawal of d-amphetamine or alpha-methyl-p-tyrosine. Psychopharmacologia (Berl.), 1973, 28, 213-234.

Houser, V. P., \& CASH, R. J. The effects of chronic morphine administration upon a modified Sidman avoidance schedule that utilizes response-independent shock. Psychopharmacologia (Berl.), 1975, 41, 255-262.

Houser, V. P., \& Houser, F. L. The effects of agents that modify muscarinic tone upon behavior controlled by an avoidance schedule that employs signaled unavoidable shock. Psychopharmacologia (Berl.), 1973, 32, 133-150.

Houser, V. P., RothFeld, B., \& VARADY, A. Effects of chlordiazepoxide upon fear-motivated behavior in dogs. Psychological Reports, 1975, 36, 987-998.

Kelleher, R. T., Riddle, W. C., \& Cook, L. Persistent behavior maintained by unavoidable shocks. Journal of the Experimental Analysis of Behavior, 1963, 6, 507-517.

LAUENER, H. Conditioned suppression in rats and the effect of pharmacological agents thereon. Psychopharmacologia (Berl.), 1963, 4, 311-325.

LOVE, W. S., \& Houser, V. P. A simple method for measuring spontaneous motor activity in squirrel monkeys during chair restraint. Physiology and Behavior, 1973, 10, 1115-1117.

Maier, S. M., Seligman, M., \& Solomon, R. Pavlovian fear conditioning and learned helplessness: Effects on escape and avoidance behavior of (a) the CS-US contingency and (b) the independence of the US and voluntary responding. In B. Campbell \& R. Church (Eds.), Punishment and aversive behavior. New York: Appleton-Century-Crofts, 1969. Pp. 299-342.

Pomerleau, O. F. The effects of stimuli followed by response-independent shock on shock avoidance behavior. Journal of the Experimental Analysis of Behavior, 1970, 14, 11-21.

RAY, O. S. Tranquilizer effects on conditioned suppression. Psychopharmacologia (Berl.), 1964, 5, 136-146.

Rescorla, R. A. Inhibition of delay in Pavlovian fear conditioning. Journal of Comparative and Physiological Psychology, 1967, 64, 114-120. 
Scobie, S. R. Interaction of an aversive Pavlovian conditional stimulus with aversively and appetitively motivated operants in rats. Journal of Comparative and Physiological Psychology, 1972, 79. 171-188.

Sidman, M. By-products of aversive control. Journal of the Experimental Analysis of Behavior, 1958, 1, 265-280.

Sidman, M.. Herrnstein, R. J., \& Conrad, D. Maintenance of avoidance behavior by unavoidable shocks. Journal of Comparative and Physiological Psychology, 1957, 50, 533-557.
Vogel, J. R., Hughes, R. A., \& Carlton, P. L. Scopolamine, atropine, and conditioned fear. Psychopharmacologia (Berl.), 1967, 10, 409-416.

WALlER, M. B., \& WALLER, P. S. The effects of unavoidable shocks on a multiple schedule having an avoidance component. Journal of the Experimental Analysis of Behavior, 1963, 6. 29-37.

(Received for publication September 8, 1975; revision accepted January 3, 1976.) 